\title{
Experimental Study on Distribution of Residual Stress for Q690 High-Strength Steel Tubes
}

\author{
Ma Tongzhuang ${ }^{1, a}$, Chen Lei ${ }^{2, b^{*}}$ \\ ${ }^{1}$ Henan D.R. Construction Group, Xinxiang, 453002, China \\ ${ }^{2}$ Henan Electric Power Survey and Design Institute, Zhengzhou 450007, China \\ a1657398597@qq.com, bchenleihe2008@163.com
}

Keywords: Supporting structures for substation; Q690 high-strength steel pipe; Residual stress; Sawing method; Blind-hole method

Abstract: With the rapid development of power transmission and transformation projects in China, steel supporting structure has already became the most popular structural form for these structures, and high-strength steel (normally means the steel with the nominal yield strength in the scope of $460 \mathrm{MPa}$ and $1100 \mathrm{MPa}$ ) have been increasingly used in recent years due to their advantages in structure safety, architecture function, economics and resource saving etc. The change of mechanical properties of high-strength steel will cause the change of load capacity of structural members. The scope of current design specifications in most countries are limited to normal strength steel (NSS) structures such as the Chinese code GB50017-2003. For high-strength steel structures, there is no design methods and theoretical basis in current design codes. For thin-walled structures, residual stress is commonly one of the disadvantages for the load capacity of structures. So it is necessary to study the form of residual stress for high-strength steel members as the basis on the load capacity research. This paper explores the form of residual stress in longitudinal direction for Q690 high-strength steel pipes with $\phi 250 \times 8 、 \phi 300 \times 8 、 \phi 350 \times 8$ using test method. Sawing method and blind-hole method are adopted for the test.

\section{General}

With the rapid development of transmission and distribution project in China, a lot of substations is under constructing. At present, application of high-strength steel in power transmission project, especially in substation frame structure, is less than that in other projects, and there is no relevant design codes. The highest strength grade of the steel we use now in substation frame structure is Q420, which is much smaller than that of Q690. The calculation model of substation frame structure is diagonal column, single column or spacial truss-beam structure. The design of component members is mainly based on the strength of tensile bars and stability of compressive bars. The dimensions of members are relatively small while using the high-strength steel. The stability of compressive bars is one of the most important influence factors of structure bearing capacity. The column curves given in "Design Code for Steel Structure" (GB50017-2003) are obtained based on the testing results using lower strength steel, which may have some difference for high strength steel.

The stability bearing capacity of steel tubes under axial load is related with the whole stability coefficient $\phi$ of members, which is affected by material, mechanical behavior and geometrical imperfection of members. The boundary conditions also have an important influence on the stability coefficient and could be considered by calculating the effective length coefficient of members. The geometrical imperfection (initial bending, initial eccentricity) can be evaluated according to general codes. The effects of boundary conditions and geometrical imperfection have little difference for high-strength steel and general used steel. However, mechanical imperfections - residual stresses could make large influence. This paper explores the form of residual stress in longitudinal direction for Q690 high-strength steel pipes with $\phi 250 \times 8 、 \phi 300 \times 8 、 \phi 350 \times 8$ using test method. Sawing method and blind-hole method are adopted for the test. The distribution and value of residual stress 
in cross-section is obtained which provides the basis for determining the whole stability coefficient $\phi$.

\section{Sawing method determining the distribution of residual stress}

\section{Specimen choosing}

The principle of sawing method is based on the hypothesis that the residual stress is distributed and changing around the circumference and keeps unchanged in longitudinal direction. Along the direction of residual stress measured, the member was cut into many narrow strips with width of $15 \mathrm{~mm} \sim 18 \mathrm{~mm}$, and the stress was derived based on the strain released which was measured by strain gauge.

The specimen was chosen from the practical members, and the length of the specimen is long enough to ensure that the distribution of the residual stress in the testing area was not disrupted. The detail of the specimen was shown in Figure 1.

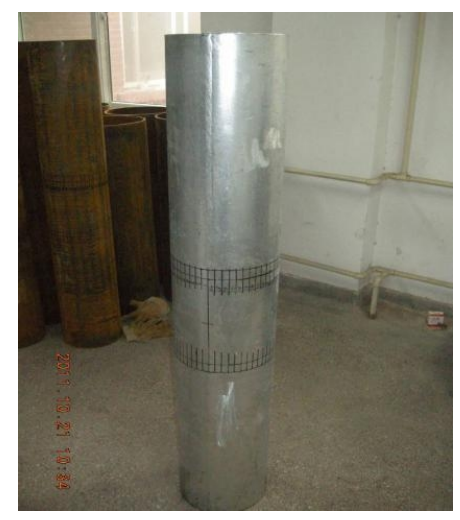

Fig.1 Specimen choosing based on sawing method

\section{Testing result}

The black specimen (non-galvanized) and white specimen (galvanized) with dimension of $\phi 250 \times 8$ was chosen for the testing by using sawing method. The results will be compared with those using blind-hole method.

The testing result for $\phi 250 \times 8$ black specimen is shown is Fig. 2. The longitudinal coordinate indicates the ratio of longitudinal residual stress to the yield strength. The results indicate that the residual stress near the area of welding are tensile stress. With the increase of distance from testing point, the value of residual stress decreased dramatically first and increased gradually after reaching the minimum value. The maximum tensile residual stress is $679.62 \mathrm{~N} / \mathrm{mm}^{2}$ which is $98.50 \%$ of the yield strength of Q690. The maximum compressive residual stress is $70.35 \mathrm{~N} / \mathrm{mm}^{2}$ which is $10.20 \%$ of the yield strength of Q690.

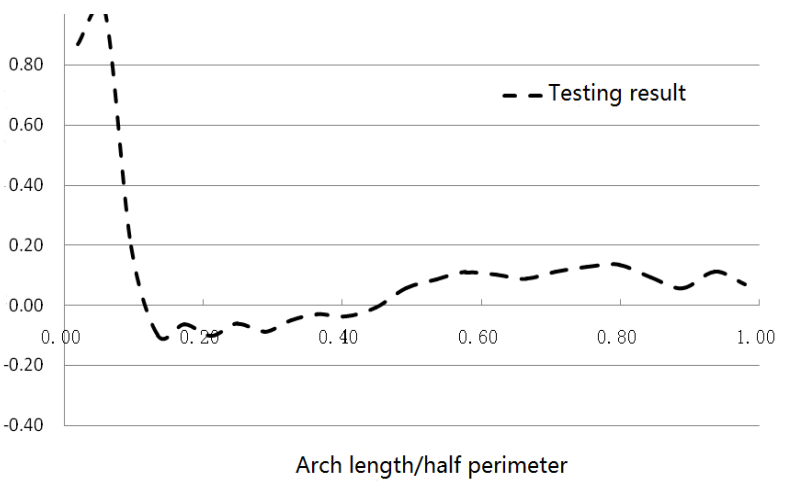

Fig. 2 Testing result for $\phi 250 \times 8$ black specimen

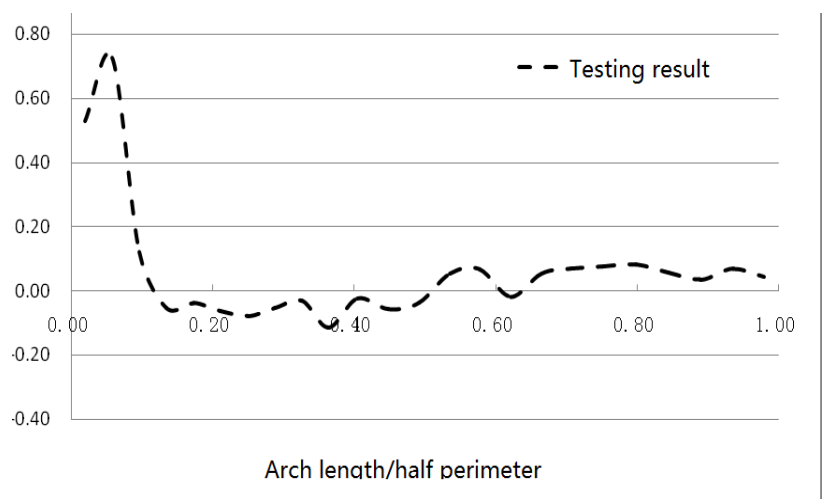

Fig.3 Testing result for $\phi 250 \times 8$ white specimen 
The testing result for $\phi 250 \times 8$ white specimen is shown is Fig. 3. The longitudinal coordinate indicates the ratio of longitudinal residual stress to the yield strength. The results indicate that the residual stress near the area of welding are tensile stress. With the increase of distance from testing point, the value of residual stress decreased dramatically first and increased gradually after reaching the minimum value. The maximum tensile residual stress is $500.12 \mathrm{~N} / \mathrm{mm}^{2}$ which is $72.48 \%$ of the yield strength of Q690. The maximum compressive residual stress is $42.91 \mathrm{~N} / \mathrm{mm}^{2}$ which is $6.22 \%$ of the yield strength of Q690.

\section{Blind-hole method determining the distribution of residual stress}

The principle of Blind-hole method is that the shallow blind hole is set at members with residual stress field, so the residual stress near the hole is released and the original stress field in the member is unbalanced which cause corresponding displacement and strain. The released strain is detected by the arranged resistance strain gauge.
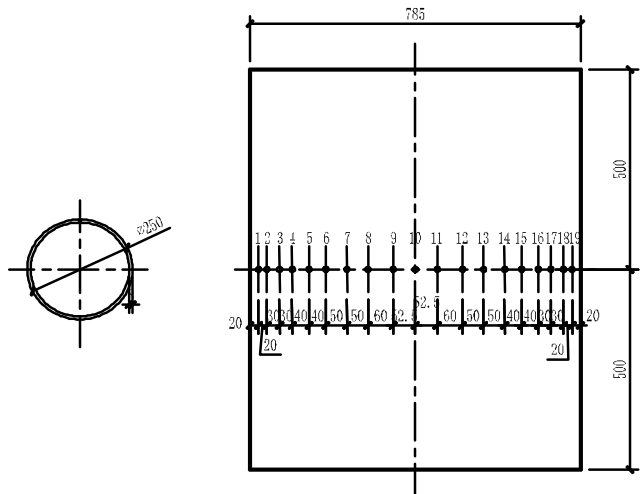

Fig.4 $\phi 250 \times 8$ Arrangement of blind hole

The position and the number of the testing point is chosen according to the shape and mechanical property of the member. The blind holes are all arranged at the middle cross-section which is shown in Fig.4 for $\phi 250 \times 8$ member. The testing procedure includes the paste of strain gauge, drilling and testing calculation. The geometric parameters for part of the testing specimen are shown in table 1 .

Table 1 Detail of testing specimen using blind-hole method

\begin{tabular}{|c|c|c|c|c|}
\hline \multicolumn{2}{|c|}{ Member Number } & \multirow[b]{2}{*}{ Dimension } & \multirow{2}{*}{$\begin{array}{l}\text { Ratio of radius to } \\
\text { thickness }\end{array}$} & \multirow{2}{*}{$\begin{array}{l}\text { Length } \\
(\mathrm{mm})\end{array}$} \\
\hline Black specimen & White specimen & & & \\
\hline HCY1-1 & BCY1-1 & \multirow{2}{*}{$\phi 250 \times 8$} & \multirow{2}{*}{31.25} & \multirow{2}{*}{1000} \\
\hline HCY1-2 & BCY1-2 & & & \\
\hline HCY2-1 & BCY2-1 & \multirow{4}{*}{$\phi 300 \times 8$} & \multirow{4}{*}{37.50} & \multirow{4}{*}{1000} \\
\hline HCY2-2 & BCY2-2 & & & \\
\hline HCY2-3 & BCY2-3 & & & \\
\hline HCY2-4 & BCY2-4 & & & \\
\hline
\end{tabular}

Only the testing results for black specimen is shown in Fig.5.The ratio of radius to thickness for specimen HCY1 is 31.25 。 The longitudinal coordinate indicates the ratio of longitudinal residual stress to the yield strength. The results indicate that the residual stress near the area of welding are tensile stress. With the increase of distance from the center of welding area, the value of residual stress decreased dramatically first and increased gradually after reaching the minimum value. The maximum tensile residual stress is $680.13 \mathrm{~N} / \mathrm{mm}^{2}$ which is $98.57 \%$ of the yield strength of Q690. The maximum compressive residual stress is $89.43 \mathrm{~N} / \mathrm{mm}^{2}$ which is $12.96 \%$ of the yield strength of Q690.

The ratio of radius to thickness for specimen HCY2 is 37.50 。 The results indicate that the residual 
stress near the area of welding are tensile stress. With the increase of distance from the center of welding area, the value of residual stress decreased dramatically first and increased gradually after reaching the minimum value. The maximum tensile residual stress is $677.46 \mathrm{~N} / \mathrm{mm}^{2}$ which is $98.18 \%$ of the yield strength of Q690. The maximum compressive residual stress is $99.38 \mathrm{~N} / \mathrm{mm}^{2}$ which is $14.40 \%$ of the yield strength of Q690.

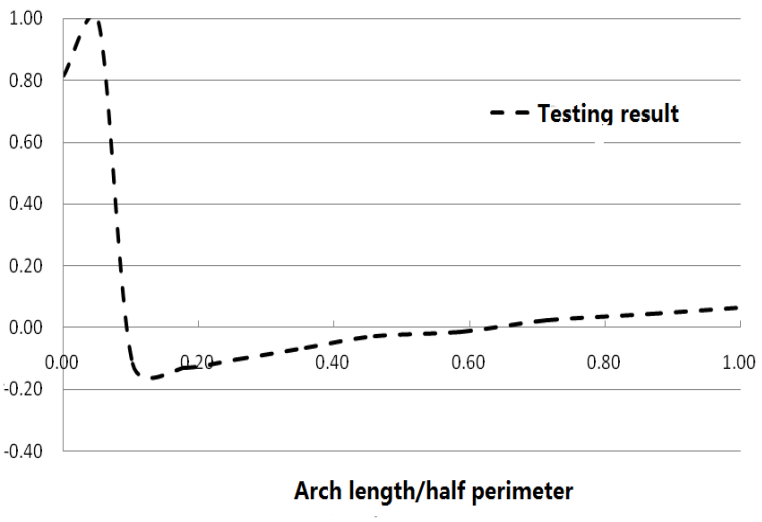

(a)HCY1

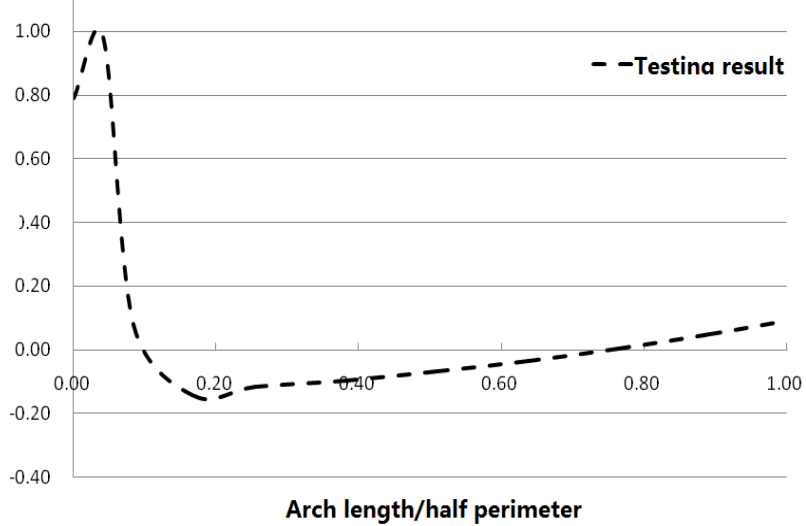

(b) HCY2

Fig. 5 Testing results for $\phi 250 \times 8$ black specimen

\section{Conclusion}

The distribution of the longitudinal residual stress for Q690 high-strength steel pipes with dimensions of $\phi 250 \times 8, \phi 300 \times 8$ was explored in this paper. The distribution form for black specimen and white specimen was derived respectively. The conclusion was obtained based on the testing data as:

(1) The residual stress is concentrated at the welding and adjacent areas. The stress gradient is large and the maximum tensile residual stress reaches the yield strength of the steel. The maximum compressive residual stress is small and is only $14.80 \%$ of the yield strength of steel, which is much smaller than that for common steel with smaller yield strength.

(2) The testing results for the residual stress of black specimen and galvanized specimen indicate that the peak value of residual stress for galvanized specimen is obviously smaller than that for black specimen, which is related with the galvanizing process of steel pipe. The process of galvanization is a process of heat treatment for steel pipe, which is helpful for eliminating the residual stress which is eliminated from $30.00 \%$ to $38.79 \%$. The galvanization is mandatory measure for anti-corrosion of steel structure, so the residual stress is reduced with no additional cost.

(3) Based on the current known testing results, the ratio of longitudinal compressive residual stress to the yield strength of the steel is obviously smaller than that for common steel pipe. The maximum ratio in this testing is 0.16 compared with the value of $0.27 \sim 0.35$ for common steel pipe.

(4) The testing results using two different methods indicate that the testing curve using sawing method fluctuates larger while the curve using blind-hole method is more stable. The reason may be that the accuracy is difficult to realize using sawing method.

\section{Reference}

[1] Code for Steel Structure Design (GB 50017-2003), Beijing: China Planning Publishing, 2003.

[2] Ban Huiyong, Shi Gang, Liu Zhao etc.: Research and test on whole stability of Q420 equilateral angle steel, Building Structures (2011), 32(2), 60-67.

[3] Rasmussen KJR, Hancock GJ. Tests of high strength columns. Journal of Constructional Steel Research 1995; 34:27-52. 
[4] Li Guoqiang, Wang Yanbo, Chen Suwen: Research and test on Q460 high strength steel weld box columns axial imitated load capacity, Building Structures, (2012), 33(3), 8-14. 